\title{
Professional self-concept and burnout among medical school faculty in South Korea: a cross-sectional study
}

\author{
Jihye Yu' ${ }^{1}$, Sukyung Lee ${ }^{2}$, Miran Kim ${ }^{*} \mathbb{D}$, Kiyoung Lim³ ${ }^{3}$ Kihong Chang ${ }^{1}$ and Sujin Chae ${ }^{4}$
}

\begin{abstract}
Background: Medical school faculty members have been reported to be highly likely to suffer burnout. Research is being conducted on professional self-concepts as a factor that relieves burnout in many professions. However, there is a paucity of data on the relationship between professional self-concept and burnout among medical school faculty. Professional self-concept means a perception of oneself as a member of the profession. It influences an individual's thoughts, actions, and emotions. The more positive the professional self-concept, the higher is the self-esteem in the profession, which can contribute to reducing burnout. This study aimed to investigate the professional self-concept and incidence of burnout among medical school clinical faculty members, and to ascertain the factors that affect professional self-concept with respect to burnout.

Methods: A total of 68 clinical faculty members at the Ajou University School of Medicine completed a modified form of the professional self-concept scale and the Maslach Burnout Inventory. We undertook the following statistical analyses: a descriptive analysis to understand the distribution of participants, correlation analysis to indicate associations between variables and a multiple regression analysis to examine the influence of gender, position, and specialty on professional self-concept and burnout, and the effect of each subscale of professional self-concept on burnout.

Results: As professional self-concept increases, burnout decreases. There was no significant difference between professional self-concept and burnout with respect to gender or field of medical specialty, while a significant difference was observed across faculty position levels. Additionally, the professional self-concept subscale, which included satisfaction and communication skill, was found to significantly affect burnout.

Conclusions: This study shows that professional self-concept affects burnout. Through these results, we can infer that professional self-concept functioned to protect medical school faculty from burnout. This may be a strategy that fortifies the professional identity of medical school faculty, and it is suggested that educational programs that are directed toward this goal be established.
\end{abstract}

Keywords: Burnout, Faculty development, Faculty of medicine, Professional self-concept

\footnotetext{
* Correspondence: kmr5300@ajou.ac.kr

'Office of Medical Education, Ajou University, Suwon, South Korea

Full list of author information is available at the end of the article
}

(c) The Author(s). 2019 Open Access This article is distributed under the terms of the Creative Commons Attribution 4.0 International License (http://creativecommons.org/licenses/by/4.0/), which permits unrestricted use, distribution, and reproduction in any medium, provided you give appropriate credit to the original author(s) and the source, provide a link to the Creative Commons license, and indicate if changes were made. The Creative Commons Public Domain Dedication waiver (http://creativecommons.org/publicdomain/zero/1.0/) applies to the data made available in this article, unless otherwise stated. 


\section{Background}

Burnout in the workplace is characterized by emotional stress associated with work or with interpersonal relationships factors such as sustained response, leading to emotional exhaustion, depersonalization, and reduced personal accomplishment [1]. It has been shown that burnout is experienced more frequently by professionals employed in providing services to treat psychological, social, and physical problems [2]. Medical school faculty members have been reported to be highly likely to suffer burnout as a result of their job activities, including student education, research, clinical practice, and other medical administrative duties [3-6]. In particular, medical faculty who are also performing clinical duties are under pressure to increase their clinical productivity and, in many cases, are urged to treat patients rather than teach students $[7,8]$. Therefore, there are numerous medical faculty members interested in student education who are unable to devote sufficient energy to teaching due to the lack of time and energy [9]. As a result, medical faculty who suffer from burnout also lose morale and experience both mental and physical problems [10].

The effects of burnout among medical faculty are not confined to the individual physician, but may result in the impairment of patient care [11], an increased incidence of medical errors and adverse events $[12,13]$, and decreased empathy towards patients [14]. Medical faculty burnout also has a detrimental effect on the education of medical students, as efforts to improve the quality of education need to be implemented; including enhanced interest in improving curricula and teaching methods. However, the ensuing physical and mental exhaustion that leads to the burnout of medical faculty may lead to passivity in accepting new and innovative changes $[15,16]$. Therefore, rather than looking for a long-term solution to medical faulty burnout, we suggest that efforts to minimize burnout should be considered so that medical practice and medical education may be performed with a high level of quality.

The majority of medical school faculty are overburdened with their respective duties, but not all faculty experience burnout. There may be individual differences even within the same workplace environment in terms of how individuals view, interpret, and handle burnout. There has been increasing attention on the idea of professional selfconcept, which reduces an individual's burnout.

Professional self-concept is the perception of what it means to be and act as member of a profession [17]. More precisely, professional self-concept refers to the perceptions of a member of a specific group with his/her skill, knowledge, beliefs, values, and motivation, which are formed and changed in the process of evaluating his/ her own traits and abilities through various experiences and interactions with others [18-21]. In other words, professional self-concepts are formed through selfreflection and social interaction. Professional selfconcept affects an individual's thoughts, behaviors, and emotions [22, 23]. Research in other areas suggests that individuals who have a strong, well-formed professional self-concept have low levels of burnout and are less willing to quit their jobs $[18,19]$. On the other hand, those who do not have a well-formed professional self-concept tend to fail to function properly in their specialties and experience a high level of exhaustion or resignation without success [24].

Studies in many professions have shown that burnout influences professional self-concept in many professional workplaces. In a study of registered nurses in a university hospital setting, it was observed that nurses who participated in a professional identity development training program experienced an enhanced professional selfconcept and lower levels of burnout [25]. Further, among professional school counselors, a negative correlation was found between professional self-concept and burnout [26].

In light of these results, it is our hypothesis that professional self-concept may be a moderating factor on burnout in medical school faculty members. However, there is a paucity of data on the relationship between professional self-concept and burnout in this highly specialized occupational group, and therefore, it is the aim of this study to delineate the role of professional selfconcept in burnout in this group.

Our research questions are as follows:

First, what is the extent/level of professional selfconcept and burnout among medical school faculty members?

Second, what are the effects of gender, job position, and medical specialty on professional self-concept and burnout in medical school faculty members?

Third, what is the relationship between professional self-concept and burnout in medical school faculty members?

\section{Methods \\ Participants}

The participants of this study were employed clinical faculty members of Ajou University School of Medicine, Gyonggi Province, Republic of Korea. The questionnaire survey, conducted in April 2018, was sent as e-mails to 230 clinical faculty members who were engaged in teaching medical students in the 2017 academic year. Consent was obtained from all participants, and the questionnaire did not include the name of the participant. A total of 68 questionnaire replies was analyzed in this study. 


\section{Measures}

\section{Professional self-concept}

To measure professional self-concept, the scale for the professional self-concept of nurses developed by Arthur [27] was used in this study, as it is a scale that can evaluate various skills and attitudes. Although developed for the nursing profession, there are no items that would be inappropriate to apply to physicians. Only items where the term "nurse" or "nursing" is used were modified for physicians for use in this study. This professional selfconcept scale consists of three subscales: professional practice, job satisfaction, and interpersonal communication. Professional practice included leadership, flexibility in adapting to one's situation, and skills to ensure a competent work performance. Job satisfaction was defined as the degree of satisfaction and joy experienced in performing one's job duties. Interpersonal communication refers to empathy and open-mindedness in interpersonal relationships. This instrument consists of 27 items: professional practice (16 items), satisfaction (7 items), and communication ( 4 items). As examples, professional practice is assessed through statements such as "Decision-making is one of my attributes," "When I'm at work and the situation calls, I am able to think of alternatives, " and "I pride myself on my skills as a doctor." Satisfaction is assessed through statements such as "Medicine is a rewarding profession." Communication is assessed through statements such as "I don't believe I am particularly empathic." Each item was scored on a fourpoint Likert scale from "strongly do not agree" (one point) to "strongly agree" (four points), and a higher score was deemed to indicate higher levels of professional self-concept. To verify the reliability of this scale, we checked the Cronbach's $\alpha$ coefficient, which was 0.925 in this study.

\section{Burnout}

To assess the degree of burnout among medical school faculty members, we employed the Maslach Burnout Inventory-Educators Survey (MBI-ES) that was developed by Maslach et al. [1]. This MBI is recognized as the leading measure of burnout and has been validated by extensive research conducted over a long period of time. This scale comprises 22 items that survey emotional exhaustion (EE, 9 items), depersonalization (DP, 5 items), and reduced personal accomplishment (RPA, 8 items). Each item in this study was measured on a seven-point rating scale ranging from "never" (zero points) to "always" (six points), and higher scores indicated more frequent burnout occurrences. Cronbach's $\alpha$ for the scale was 0.905 .

\section{Analysis}

To understand the distribution of participants by gender, job position, and job specialty, and to ascertain the characteristics of the questionnaire participants, descriptive statistical methods were applied. To identify the relationships between the subscales of variables, correlation analysis was conducted. Multiple regression analysis was carried out to analyze the effects of gender, faculty position, and field of specialty on professional self-concept and burnout. Multiple regression analysis was also applied to analyze the effects of the variables assessed by the professional self-concept subscales on burnout.

\section{Results}

\section{Demographics}

The distribution of gender, faculty position, and field of specialty of the study participants is shown in Table 1 . Out of the 230 participants, 68 of them responded (29.6\%), and the gender ratio was found to be 1.5 (M:F ratio). The distribution of faculty positions was fairly even, while the most common field of specialty was internal medicine, followed by surgery, and support care medicine.

The analyses of participants' professional self-concept and burnout are shown in Table 2 .

Among the professional self-concept subscales, participants scored the highest on professional practice $(M=$ $3.30, S D=0.41)$, followed by satisfaction $(M=3.06, S D=$ $0.56)$, and communication $(M=2.89, S D=0.51)$; while on the subscales of professional practice, participants scored the highest for skill $(M=3.44, S D=0.38)$ followed by flexibility $(M=3.37, S D=0.42)$, and leadership $(M=$ 3.10, $S D=0.54)$.

Participants' scores on the subscales for burnout were ranked as follows: emotional exhaustion $(M=3.02, S D=$ $0.99)$, reduced personal accomplishment $(M=2.16, S D=$ $0.94)$, and depersonalization $(M=2.01, S D=1.14)$, in decreasing order.

Table 1 Characteristics of participants $(N=68)$

\begin{tabular}{ll}
\hline Variable & $N(\%)$ \\
\hline Gender & $41(60.3)$ \\
Male & $27(39.7)$ \\
Female & \\
Faculty Position & $27(39.7)$ \\
Assistant professor & $20(29.4)$ \\
Associate professor & $21(30.9)$ \\
Professor & \\
Field of Specialty & $30(44.1)$ \\
Internal medicine & $21(30.9)$ \\
Surgery & $17(25.0)$ \\
Supportive care medicine &
\end{tabular}

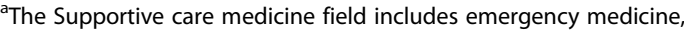
rehabilitation medicine, anesthesiology, radiology, and clinical pathology 
Table 2 Means, standard errors, and standard deviations for professional self-concept and burnout

\begin{tabular}{llll}
\hline Variable & Mean & SE & SD \\
\hline PSC & 3.09 & 0.05 & 0.41 \\
Professional practice & 3.30 & 0.05 & 0.41 \\
$\quad$ Leadership & 3.10 & 0.07 & 0.54 \\
Flexibility & 3.37 & 0.05 & 0.42 \\
$\quad$ Skill & 3.44 & 0.05 & 0.38 \\
Satisfaction & 3.06 & 0.07 & 0.56 \\
Communication & 2.89 & 0.06 & 0.51 \\
Burnout & 2.39 & 0.10 & 0.85 \\
EE & 3.02 & 0.12 & 0.99 \\
DP & 2.01 & 0.14 & 1.14 \\
RPA & 2.16 & 0.11 & 0.94 \\
\hline PSC Profess &
\end{tabular}

PSC Professional Self-Concept, EE Emotional Exhaustion, DP Depersonalization, RPA Reduced Personal Accomplishment

The correlations between variables are shown in Table 3. It can be seen that there exists a statistically significant negative correlation $(r=-0.76, p<0.01)$ between professional self-concept and burnout, indicating that higher professional self-concept values lead to lower burnout values. All the subscales of professional self-concept showed significant negative correlations with burnout, with their absolute values decreasing from 0.69 for satisfaction $(p<0.01)$ to 0.60 for communication $(p<0.01)$ and professional practice $(p<0.01)$.

We investigated the effects of gender, faculty position, and field of specialty on professional self-concept and burnout as reported in Table 4. Gender and field of specialty were not found to be associated with professional self-concept and burnout, while faculty position did significantly affect them. Faculty position had a positive effect on professional self-concept, but a negative effect on burnout.

The analysis of the effect of professional self-concept on burnout is shown in Table 5. Professional self-concept explained $60 \%$ of the variance $(F=30.13, p<0.001)$ for

Table 3 The relationship between professional self-concept and the burnout subscales

\begin{tabular}{lllll}
\hline & Burnout & EE & DP & RPA \\
\hline PSC & $-0.76^{* *}$ & $-0.59^{* *}$ & $-0.51^{* *}$ & $-0.83^{* *}$ \\
Professional practice & $-0.60^{* *}$ & $-0.40^{* *}$ & $-0.38^{* *}$ & $-0.74^{* *}$ \\
Leadership & $-0.63^{* *}$ & $-0.41^{* *}$ & $-0.42^{* *}$ & $-0.78^{* *}$ \\
Flexibility & $-0.56^{* *}$ & $-0.37^{* *}$ & $-0.36^{* *}$ & $-0.69^{* *}$ \\
Skill & $-0.41^{* *}$ & $-0.29^{*}$ & -0.24 & $-0.52^{* *}$ \\
Satisfaction & $-0.69^{* *}$ & $-0.65^{* *}$ & $-0.43^{* *}$ & $-0.65^{* *}$ \\
Communication & $-0.60^{* *}$ & $-0.38^{* *}$ & $-0.46^{* *}$ & $-0.68^{* *}$ \\
\hline
\end{tabular}

${ }^{*} p<0.05,{ }^{* *} p<0.01$

PSC Professional Self-Concept, EE Emotional Exhaustion, DP Depersonalization, RPA Reduced Personal Accomplishment
Table 4 Multiple regression analysis for professional selfconcept and burnout

\begin{tabular}{|c|c|c|c|c|c|c|}
\hline \multirow[t]{2}{*}{$\begin{array}{l}\text { Dependent } \\
\text { variable }\end{array}$} & \multirow[t]{2}{*}{$\begin{array}{l}\text { Independent } \\
\text { variable }\end{array}$} & $\begin{array}{l}\text { Standardized } \\
\text { Coefficients }\end{array}$ & $t$ & \multirow[t]{2}{*}{$R^{2}$} & \multirow[t]{2}{*}{$\begin{array}{l}\text { adj. } \\
R^{2}\end{array}$} & \multirow[t]{2}{*}{$F$} \\
\hline & & $\beta$ & & & & \\
\hline \multirow[t]{4}{*}{ PSC } & & & & 0.13 & 0.09 & 3.17 \\
\hline & Gender & -0.03 & -0.21 & & & \\
\hline & Position & 0.35 & $2.91^{* *}$ & & & \\
\hline & Specialty & -0.10 & -0.83 & & & \\
\hline \multirow[t]{4}{*}{ Burnout } & & & & 0.29 & 0.25 & 8.50 \\
\hline & Gender & 0.05 & 0.46 & & & \\
\hline & Position & -0.51 & $-4.70^{* * *}$ & & & \\
\hline & Specialty & -0.08 & -0.74 & & & \\
\hline
\end{tabular}

burnout. It was also observed that while professional practice did not have a significant effect on burnout, satisfaction $(\beta=-0.41, p<0.001)$ and communication $(\beta=-0.30$, $p<0.01)$ had significant negative effects.

\section{Discussion}

This study investigated the effect of professional selfconcept on burnout in medical school clinical faculty members. The study results are as follows.

First, the analysis of the relationship between professional self-concept and burnout found negative correlations between professional self-concept and all burnout subscales, emotional exhaustion, depersonalization, and reduced personal accomplishment. That is, medical faculty with higher levels of professional self-concept experience less burnout. Our results can be understood within the framework of Edwards and Dirette [28], whose study demonstrated a significant negative correlation between occupational therapists' professional self-concept and burnout. Our results confirm that strengthening the level of professional self-concept could lead to decreases in burnout occurrences. In particular, the results show that professional self-concept is strongly and positively related to the personal accomplishment sub-scale of the MBI. Hence professional self-concept appears to be strongly influenced by experiencing a sense of competence and accomplishment in one's field of expertise.

Second, it was found that the higher the faculty position, the higher the level of professional self-concept with accompanying lower levels of burnout. This implies that junior faculty members experience lower levels of professional self-concept than senior faculty members, and have concomitantly higher levels of burnout. Earlier investigations of medical school faculty burnout [29-31], concluded that in their early career years, faculty were more susceptible to high levels of emotional exhaustion, which agrees with our results. The reason senior faculty 
Table 5 Multiple regression analysis for burnout

\begin{tabular}{lllll}
\hline Variable & \multicolumn{2}{l}{ Unstandardized Coefficients } & \multicolumn{2}{l}{ Standardized Coefficients } \\
\cline { 2 - 4 } & $B$ & Std. Error & $\beta$ & -0.21 \\
\hline Professional practice & -0.43 & 0.22 & -0.41 & -1.98 \\
Satisfaction & -0.62 & 0.16 & -0.30 & $-3.85^{* * *}$ \\
Communication & -0.50 & 0.16 & \\
$R^{2}=0.59$, adj. $R^{2}=0.57, F=30.13^{* * *}$ & & &
\end{tabular}

have less burnout than junior faculty may be understood in terms of accumulated career experience, which is accompanied by enhanced job skills and control abilities so that high standards of competence are achieved, leading to relatively decreased job-related stress or burnout $[29,32]$. In addition, junior faculty members work longer hours than senior faculty members, receive more emergency calls, and are subject to irregular work-life problems [33, 34]. Family environment may also be a contributing factor for burnout. Junior faculty are younger and frequently have families with young children to support [30], which may be contributing factors to conflict and burnout in the workplace and at home.

Third, while the subscales of professional self-concepts, such as leadership, flexibility, and skill did not have a significant effect on burnout, our study found that job satisfaction and communication factors had a significant negative effect. Medical school faculty form various interpersonal networks with patients, medical students, nurses, and administrative staffs in two workplace environments-at hospital and at school. The difficulty in interpersonal communication is a factor that elevates the degree of burnout. It was shown in an earlier analytic study of the relationship between burnout and job satisfaction in surgeons that lower job satisfaction was correlated with a significantly greater incidence of burnout [9]. Another study addressed the relationship between registered nurses' training in communication skills and burnout, and determined that communication skill training played an active role in ameliorating burnout among nurses [35]. We were therefore able to ascertain from the aforementioned studies whether the extent of medical school faculty satisfaction with their duties and how well they are able to communicate with whom they interact in their workplace significantly affect their levels of burnout.

The significance and implications of this study are as follows.

First, the main point of the current study is that we were able to explore the relationship between professional self-concept, and confirm the function of professional self-concept in ameliorating this burnout. The findings of the study do not necessarily demonstrate a causal relationship between professional self-concept and burnout. Nonetheless, it may be considered that professional self-concept is a possible factor serving a protective function for the medical faculty member's mental well-being. In particular, it is our opinion that one of the major findings of this explorative inquiry is the confirmation of the significant role of job satisfaction and interpersonal communication skills in reducing the degree of burnout among medical faculty.

Second, we would point out that junior medical faculty have low levels of professional self-concept and high burnout rates. To enhance their professional self-concept levels and decrease burnout rates, junior medical faculty need faculty development and mentoring programs. We suggest that these results be brought to the attention of medical school deans and administrations so that necessary institutional support can be provided.

Nevertheless, we must note the limitations of the current study to suggest directions for future follow-up studies. We find the distribution of gender, position, and specialty to be relatively balanced, even with a small number of participants. In particular, we think the $6: 4$ gender ratio in this study is not terribly important. Nevertheless, this study has limitations in that it was conducted in one medical school with a small sample. It is necessary to conduct follow-up studies in more number of medical schools with larger samples. Moreover, this study applied a standardized questionnaire that assessed self-reported measures; other standardized instruments could also be used advantageously. Professional self-concept is one aspect of the educational process that gradually develops through adaptation to job duties, and therefore requires continuous evaluation at each step over a long period. There is also a limitation in the overall measurement of burnout, and the use of quantitative instruments to measure the psychodynamic aspects of this psychological phenomena. To better understand the burnout phenomenon, in-depth interviews along with qualitative research is deemed imperative.

\section{Conclusions}

This study ascertained that professional self-concept functions to protect medical school faculty from burnout. This may be a strategy that fortifies the professional identity of medical school faculty, and it is suggested that educational programs directed toward this goal be established. 


\section{Abbreviations}

DP: Depersonalization; EE: Emotional Exhaustion; MBI-ES: Maslach Burnout Inventory-Educators Survey; PSC: Professional Self-Concept; RPA: Reduced Personal Accomplishment

\section{Acknowledgements}

Not applicable.

\section{Authors' contributions}

YJH, KMR developed the study concept and design. YJH analyzed and interpreted the data, and drafted the manuscript. LSK acquired the data. $\mathrm{CKH}$ assisted in interpreting the manuscript. LKY revised the manuscript. CSJ assisted in the interpretation of the data, and revised the manuscript. KMR critically revised the manuscript and supervised the study. All authors read and approved the final manuscript.

\section{Funding}

No funding was obtained for this study.

\section{Availability of data and materials}

The dataset used during the current study is available from the

corresponding author upon reasonable request.

\section{Ethics approval and consent to participate}

This study was approved by the Institutional Review Board (IRB) of Ajou University Hospital (Ethics consent No. AJIRB-SBR-SUR-18-069). Consent forms were obtained from all survey participants.

\section{Consent for publication}

Not applicable.

\section{Competing interests}

The authors declare that they have no competing interests.

\section{Author details}

${ }^{1}$ Office of Medical Education, Ajou University, Suwon, South Korea. ${ }^{2}$ Ajou Center for Clinical Excellence, Ajou University, Suwon, South Korea. ${ }^{3}$ Department of Psychiatry, Ajou University, Suwon, South Korea. ${ }^{4}$ Department of Medical Education, Catholic Kwandong University College of Medicine, Incheon, South Korea.

Received: 23 August 2018 Accepted: 24 June 2019

Published online: 05 July 2019

\section{References}

1. Maslach C, Jackson SE, Leiter MP. Maslach burnout inventory manual. 3rd ed. Palo Alto, CA: Consulting Psychologists Press; 1996.

2. Freudenberger HJ. The staff burnout. J Soc Issues. 1974;30:19-27.

3. Campbell DA Jr, Sonnad SS, Eckhauser FE, Campbell KK, Greenfield LJ. Burnout among American surgeons. Surgery. 2001;130:696-705.

4. Shanafelt T, Sloan J, Habermann T. The well-being of physicians. Am J Med. 2003;114:513-7.

5. Spickard A Jr, Gabbe SG, Christensen JF. Mid-career burnout in generalist and specialist physicians. JAMA. 2002;288:1447-50.

6. Tijdink JK, Vergouwen ACM, Smulders YM. Publication pressure and burn out among Dutch medical professors: a nationwide survey. PLoS One. 2013; 8:e7338.

7. Coverdill JE, Finlay W, Adrales GL, Mellinger JD, Anderson KD, Bonnell BW, Cofer JB, Dorner DB, Haisch C, Harold KL, et al. Duty-hour restrictions and the work of surgical faculty: results of a multi-institutional study. Acad med. 2006. 2006;81:50-6.

8. Reed DA, Levine RB, Miller RG, Ashar BH, Bass EB, Rice TN, Cofrancesco J Jr. (2007). Effect of residency duty-hour limits: views of key clinical faculty. Arch. Intern. Med. 2007;167:1487-92

9. Shanafelt TD, Balch CM, Bechamps GJ, Russell T, Dyrbye L, Satele D, Collicott P, Novotny PJ, Sloan J, Freischlag JA. Burnout and career satisfaction among American surgeons. Ann Surg. 2009;250:463-71.

10. Cruz OA, Pole CJ, Thomas SM. Burnout in chairs of academic departments of ophthalmology. Ophthalmology. 2007;114:2350-5.
11. Shanafelt TD, Bradley KA, Wipf JE, Back AL. Burnout and self-reported patient care in an internal medicine residency program. Ann Intern Med. 2002;136:358-67.

12. West CP, Huschka MM, Novotny PJ, Sloan JA, Kolars JC, Habermann TM, Shanafelt TD. Association of perceived medical errors with resident distress and empathy: a prospective longitudinal study. JAMA. 2006;296:1071-8.

13. West CP, Tan AD, Habermann TM, Sloan JA, Shanafelt TD. Association of resident fatigue and distress with perceived medical errors. JAMA. 2009;302:1294-300.

14. Thomas MR, Dyrbye LN, Huntington JL, Lawson KL, Novotny PJ, Sloan JA, Shanafelt TD. How do distress and well-being relate to medical student empathy? A multicenter study. J Gen Intern Med. 2007;22:177-83.

15. Arvandi Z, Emami A, Zarghi N, Alavinia SM, Shirazi M, Parikh SV. Linking medical faculty stress/burnout to willingness to implement medical school curriculum change: a preliminary investigation. J Eval Clin Pract. 2016;22:86-92.

16. Hays RB, Jolly BC, Caldon LJM, McCrorie P, McAvoy PA, McManus IC, Rethans JJ. Is insight important? Measuring capacity to change performance. Med Educ. 2002;36:965-71.

17. Fagermoen MS. Professional identity: values embedded in meaningful nursing practice. J Adv Nurs. 1997;25:434-41.

18. Friedman IA, Farber BA. Professional self-concept as a predictor of teacher burnout. J Educ Res. 1992;86(1):28-35.

19. Beijaard D, Verloop N, Vermunt JD. Teachers' perceptions of professiona identity: an exploratory study from a personal knowledge perspective. Teach Educ. 2000:16:749-64.

20. Crossley J, Vivekananda-Schmidt P. The development and evaluation of a professional self identity questionnaire to measure evolving professional self-identity in health and social care students. Med Teach. 2009;31:603-7.

21. Cruess RL, Cruess SR, Boudreau JD, Snell L, Steinert Y. Reframing medical education to support professional identity formation. Acad Med. 2014;89: 1446-51.

22. Moss JM, Gibson DM, Dollarhide CT. Professional identity development: a grounded theory of transformational tasks of counselors. J Couns Dev. 2014;92:3-12.

23. Slay HS, Smith DA. Professional identity construction: using narrative to understand the negotiation of professional and stigmatized cultural identities. Hum Relat. 2011:64:85-107.

24. Senter A, Morgan RD, Serna-McDonald C, Bewley M. Correlational psychologist burnout, job satisfaction, and life satisfaction. Psychol Serv. 2010;7:190-201

25. Sabanciogullari S, Dogan S. Effects of the professional identity development programme on the professional identity, job satisfaction and burnout levels of nurses: a pilot study. J Nurs Pract. 2015;21:847-57.

26. Bulter $\mathrm{S}$, Constantine M. Collective self-esteem and burnout in professional school counselors. Sch Couns. 2005:9:55-62.

27. Arthur D. Measurement of the professional self-concept of nurses: developing a measurement instrument. Nurse Educ Today. 1995;15:328-35.

28. Edwards H, Dirette D. The relationship between professional identity and burnout among occupational therapists. Occup Ther Health Care. 2010;24:119-29.

29. Peisah C, Latif E, Wilhelm K, Williams B. Secrets to psychological success: why older doctors might have lower psychological distress and burnout than younger doctors. Aging Ment Health. 2009;13:300-7.

30. Tijdink JK, Vergouwen AC, Smulders YM. Emotional exhaustion and burnout among medical professors: a nationwide survey. BMC Med Educ. 2014;14:183.

31. Schindler BA, Novack DH, Cohen DG, et al. The impact of the changing health care environment on the health and well-being of faculty at four medical schools. Acad Med. 2006:81(1):27-34.

32. Keeton K, Fenner DE, Johnson TR, Hayward RA. Predictors of physician career satisfaction, work-life balance, and burnout. Obstet Gynecol. 2007; 109:949-55

33. Dyrbye LN, Varkey P, Boone SL, Satele DV, Sloan JA, Shanafelt TD. Physician satisfaction and burnout at different career stages. Mayo Clin Proc. 2013;88: 1358-67.

34. Shanafelt TD, West CP, Sloan JA, Novotny PJ, Poland GA, Menaker R, Rummans TA, Dyrbye LN. Career fit and burnout among academic faculty. Arch Intern Med. 2009;169:990-5.

35. Shimizu T, Mizoue T, Kubota S, Mishima N, Nagata S. Relationship between burnout and communication skill training among Japanese hospital nurses: a pilot study. J Occup Health. 2003;45:185-90.

\section{Publisher's Note}

Springer Nature remains neutral with regard to jurisdictional claims in published maps and institutional affiliations. 